\title{
The Effect of Spiritual Intelligence and Optimistic on Creativity in Team and Individual Sports Activities of Trabzon University Students
}

\author{
Elif Aydin \\ Faculty of Physical Education and Sport Sciences, Gumuhshaneh University, Turkey. \\ Email:aydinelif6129@gmail.com Tel:00905302659515
}

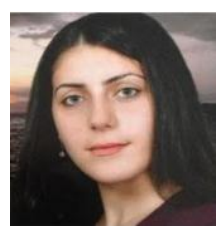

\begin{abstract}
The main purpose of this research was to investigate the effect of spiritual intelligence and optimistic on creativity of team and individual athletes of Trabzon University. In order to measure the spiritual intelligence, the optimism and the creativity variable, the standard questionnaires (Amram and Dryer, 2008), (Webber and Smokowski, 2018) and (Torrance, 2000) were used respectively. The reliability of the questionnaires was also evaluated by Cronbach's alpha test, respectively. The Cronbach's alpha coefficient for the spiritual intelligence, optimism and creativity questionnaires were $0.75,0.83$, and 0.81 respectively. The questionnaires were comprised of a sample of 148 students from Trabzon University: 74 of team athletes such as soccer, volleyball, basketball and handball as well as 74 individual athletes such as tennis, badminton, track and field, swimming, etc.. The findings showed that: spiritual intelligence and optimism has a significant effect on creativity of all team and individual athletes. Spiritual intelligence and optimism has a significant effect on creativity of individual athletes. Team and individual athletes have a significant difference in optimism and creativity variables. So the observed significant difference was due to more creativity of team sportsmen.
\end{abstract}

Keywords: Spiritual intelligence, Optimism, Creativity, Team sports, Individual sports.

Citation | Elif Aydin (2019). The Effect of Spiritual Intelligence and Optimistic on Creativity in Team and Individual Sports Activities of Trabzon University Students. Asian Journal of Activities of Trabzon University
Education and Training, 5(3): 397-402.

History:

Received: 5 April 2019

Revised: 10 May 2019

Accepted: 19 June 2019

Accepted: 19 June 2019

Licensed: This work is licensed under a Creative Commons

Licensed: This work is
Attribution 3.0 License (cc) E

Publisher: Asian Online Journal Publishing Group
Funding: This study received no specific financial support.

Competing Interests: The author declares that there are no conflicts of Competing Interests: The author declares that
interests regarding the publication of this paper.

Transparency: The author confirms that the manuscript is an honest, accurate, and transparent account of the study was reported; that no vital features of the study have been omitted; and that any discrepancies from the study as planned have been explained.

Ethical: This study follows all ethical practices during writing.

\section{Contents}

1. Introduction

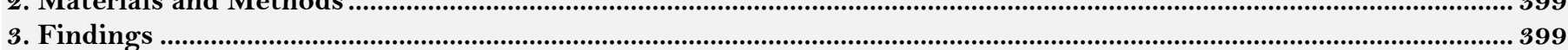

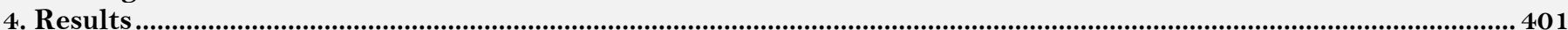

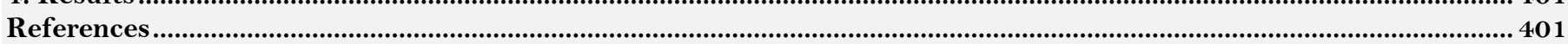




\section{Contribution of this paper to the literature}

This study contributes to the existing literature by investigating the effect of spiritual intelligence and optimistic on creativity of team and individual athletes of Trabzon University.

\section{Introduction}

Creativity in its special meaning as the supreme mental characteristic of its productive man reflects the balanced and transcendent growth of personality (Almajali, 2009) and responds to the ever-increasing need of man to break down the impasse and go beyond (Brink, 2004). Psychologists believe that creativity is one of the constituents of the performance or the function of the mind (Kalischuk and Thorpe, 2002) although it is difficult to measure and possibly impossible (Luftig, 2000). In the contemporary world, having creative thoughts is a factor in individual and social development (MacDonald and Bigelow, 2010) and the education of those who are able to face and solve problems based on creative thinking and are always creative in their activities is the ultimate goal of developing societies (Matthews, 2011).

Sports activities, like all other activities, require creativity to progress and achieve better results and achieve desired goals. If athletes and physical education students can not be creative enough in their sporting and educational activities, and if they are faced with problems and problems or in their activities based on existing stereotypes, they will not be able to make stairs and Progress is well done. Problems in any field can be solved by existing methods and methods, if they were not resolved, or could be solved over time, so that their creativity in applying methods could be used to transpose them and make success available (Sindane, 2011).

Psychological variables such as human intelligence or their psychological characteristics can also affect creativity in their sports activities. Therefore, it is necessary to find effective psychological variables in this field by scientific studies and research. Spiritual intelligence as well as optimism in individuals and among students are among these variables that seem to have the ability to influence the creativity of physical education students.

Meaningful, purposeful and satisfying is one of the attributes that can be achieved for people with a lot of spiritual intelligence and by creating spirituality in activities (Rostami and Hayedeh, 2014). In fact, spirituality in activities describes the experiences of people whose work Satisfying, meaningful and purposeful. The experience of spirituality is also accompanied by increased creativity, honesty, trust, and commitment in activities (Upadhyay and Upadhyay, 2016). In recent years, there has been a lot of evidence and intelligence on the existence of intelligence called Spiritual Intelligence. According to recent findings, this intelligence is the ultimate in human intelligence and a turning point in this field (Silingienè and Škerienè, 2015). Today, one of the subjects in the field of individual, social and even occupational activities is the subject of ethics and spiritual capital, we must be able to prove that we are not human beings who think only money, but we are beings that have a certain meaning and meaning in our lives and we seek to find meaning and purpose for our lives (Matthews, 2011) Spiritual intelligence is the ability to give us the power to see dreams and effort to achieve those dreams. This intelligence is all that we believe in, and the role of beliefs, beliefs and values in the activities we undertake. The intelligence by which we ask questions about fundamental issues in our lives, and with this help, transformation and transformation into life (Yang and Mao, 2007) the intelligence that we are capable of through actions and methods Our functions are broader, richer, more generous and meaningful. It also helps to understand the meaning of our actions and find out which of our actions and behaviors are worth more, and which paths in our lives are worthwhile and worthwhile (Kalantarkousheh et al., 2014).

Also, optimism is also a combination of optimistic attitudes about oneself, people, things, events, and in general the world (Matthews, 2011) based on which expectations of good and promising results, based on their abilities, are in the good ones with the health and the root of this optimistic attitude in the style of explanation of individuals (Kelberer et al., 2018) If ordinary human perceptions come with a positive self-concept and personal control and an optimistic view of the future, not only in the tidal management of daily life, but also in the face of extreme stressful and life-threatening events, to individuals Helps (Gabriel et al., 2018).

If Physical education students have the necessary optimism in their sports activities, appear to have less hurdles by relying on optimistic variable components to employ optimistic methods to solve existing problems or to exercise sports activities (Hilary et al., 2016). Because they are optimistic about using innovative methods and solutions and their outcomes, and the desire to use these methods is easier for them (Shepperd et al., 2017).

Creativity in sporting activities and their success is a very important factor that can not be neglected in the success of sports victories. There are steps in performing or sports competitions that if a person does not have the creativity and does not have problems and procedures using the innovative method, he can not guarantee progress in exercise, because the use The stereotyped and former methods will have the same results as the previous ones and will be incapable of dealing with new issues. Several factors can have a particular impact on creativity in general and athletic creativity, among which psychological variables can not be neglected. Types of intelligence, including cultural intelligence, as well as having different personal morals, such as optimism or pessimism in one context, can be important. Spiritually intelligent individuals are often mentally restrained and self-restrained, and have a good mental and emotional readiness for creativity, and individuals with more optimism will be more comfortable applying creative approaches to issues. All of these can have different consequences for individual and team sports. In team sports, spiritual intelligence and optimism may have a direct relationship to his creativity, but in team sports, the spiritual intelligence of individuals and their optimism for teamwork and teamwork, or team decisions, will have a dialectical relationship. Spiritual intelligence of individuals and their spirituality in the conduct of their activities as well as their optimism may, in addition to their activities affect others, or affect them. Hence, team and individual sports will be important in this regard.

Therefore, in this research, in addition to studying the effect of spiritual intelligence and optimism on creativity in team and individual sports activities of Trabzon University students, the possibility of significant difference in spiritual intelligence, optimism and creativity of physical education students in sports team members (football, volleyball, basketball, handball, etc.) and individual (tennis, badminton, diving, swimming, etc.) have been addressed. 


\section{Materials and Methods}

The present research is applied in terms of the purpose of the research, in terms of method, descriptive and correlation. Therefore, in terms of data collection method, the research method is a survey strategy. The statistical population of this research is all physical education students active in team and individual sports of Trabzon University, in number of 250 , and a sample size of 148 was determined using the Morgan table. The statistical sample was stratified random sampling (74 students from the active students in team sports such as football, volleyball, basketball and handball and 74 students in active classes of individual sports such as tennis, badminton, diving, swimming, etc.) are selected among members of the statistical community.

In order to measure the spiritual intelligence variable, the standard questionnaire (Amram and Dryer, 2008) was used to measure the optimism variables by standard questionnaire (Webber and Smokowski, 2018) and also for measuring the creativity variable in exercise activities standard questionnaire (Torrance, 2000). Cronbach's alpha coefficient for the spiritual intelligence questionnaire was 0.75 , 0.83 for the optimism questionnaire and 0.81 for the creativity questionnaire. For statistical analysis of the research data, SPSS 20 software and multivariate regression test as well as T- independent groups have been used.

\section{Findings}

Table-1. The effect of spiritual intelligence and optimism on creativity in individual and team sport activities of Trabzon University students.

\begin{tabular}{|c|c|c|c|c|c|c|}
\hline & \multirow{2}{*}{ Model } & \multicolumn{2}{|c|}{ Unstandardized Coefficients } & \multirow{2}{*}{$\begin{array}{c}\text { Standardized Coefficients } \\
\text { Beta }\end{array}$} & \multirow{2}{*}{$\mathbf{T}$} & \multirow{2}{*}{ Sig. } \\
\hline & & B & Std. Error & & & \\
\hline \multirow{3}{*}{1} & (Constant) & -.437 & .321 & & -1.363 & .175 \\
\hline & Spiritual Intelligence & .481 & .093 & .379 & 5.191 & .000 \\
\hline & Optimism & .477 & .107 & .326 & 4.471 & .000 \\
\hline
\end{tabular}

a. Dependent Variable: Creativity.

According to the results of Table 1 (considering the significant level of test error, sig. Or p, which for both variables "spiritual intelligence" and "optimism" is less than 0.05), and considering the beta coefficients, we can say that the maximum power The prediction with the beta coefficient of 0.379 is related to the spiritual intelligence variable, followed by the "optimism" variable with a beta score of 0.326 , which predicts creativity in individual team and individual sports activities of Trabzon University students. It can be concluded that the variable "spiritual intelligence" affects and improves slightly more than the "optimism" variable on creativity in team and individual sports activities (all students).

Table-2. The effect of spiritual intelligence and optimism on creativity in Trabzon University students' sports activities.

\begin{tabular}{|c|c|c|c|c|c|c|}
\hline & \multirow{2}{*}{ Model } & \multicolumn{2}{|c|}{ Unstandardized Coefficients } & \multirow{2}{*}{$\begin{array}{c}\text { Standardized Coefficients } \\
\text { Beta }\end{array}$} & \multirow{2}{*}{$\mathbf{t}$} & \multirow{2}{*}{ Sig } \\
\hline & & B & Std. Error & & & \\
\hline \multirow{3}{*}{1} & (Constant) & -.864 & .379 & & -2.280 & .026 \\
\hline & Spiritual Intelligence & .501 & .102 & .436 & 4.924 & .000 \\
\hline & Optimism & .660 & .135 & .434 & 4.895 & .000 \\
\hline
\end{tabular}

According to the results of Table 2 (considering the significant level of test error, sig. Or p, which for both variables "spiritual intelligence" and "optimism" is less than 0.05), and considering the beta coefficients, we can say that the maximum power The prediction with the 0.436 beta coefficient is related to the spiritual intelligence variable, followed by the "optimism" variable with a beta coefficient of 0.434 , which predicts creativity in team activities at Trabzon University students. It can be concluded that the variable "spiritual intelligence" affects and improves the "optimism" variable on creativity in team sports activities of students.

Table-3. The effect of spiritual intelligence and optimism on creativity in individual sports activities of Trabzon University students.

\begin{tabular}{|c|c|c|c|c|c|c|}
\hline & \multirow{2}{*}{ Model } & \multicolumn{2}{|c|}{ Unstandardized Coefficients } & \multirow{2}{*}{$\begin{array}{c}\text { Standardized Coefficients } \\
\text { Beta }\end{array}$} & \multirow{2}{*}{$\mathbf{t}$} & \multirow{2}{*}{ Sig. } \\
\hline & & B & Std. Error & & & \\
\hline \multirow{3}{*}{1} & (Constant) & -.328 & .514 & & -.639 & .525 \\
\hline & Spiritual Intelligence & .452 & .153 & .328 & 2.958 & .004 \\
\hline & Optimism & .427 & .162 & .292 & 2.630 & .010 \\
\hline
\end{tabular}

a. Dependent Variable: Creativity.

According to the results of Table 3 (considering the significant level of test error, sig. Or p, which for both variables "spiritual intelligence" and "optimism" is less than 0.05), and considering the beta coefficients, we can say that the maximum power The prediction with the coefficient of 0.328 is related to the spiritual intelligence variable, followed by the "optimism" variable with a beta coefficient of 0.292 that predicts creativity in individual sports activities of Trabzon University students. It can be concluded that the variable "spiritual intelligence" affects and improves the "optimism" variable on creativity in solitary sports activities of students.

According to the results of Table 4, according to the significance level [Sig. (2-tailed) or P] which is greater than 0.05 , it can be concluded that there is no significant difference between the students of team and individual sports of Trabzon University in the spiritual intelligence variable. 


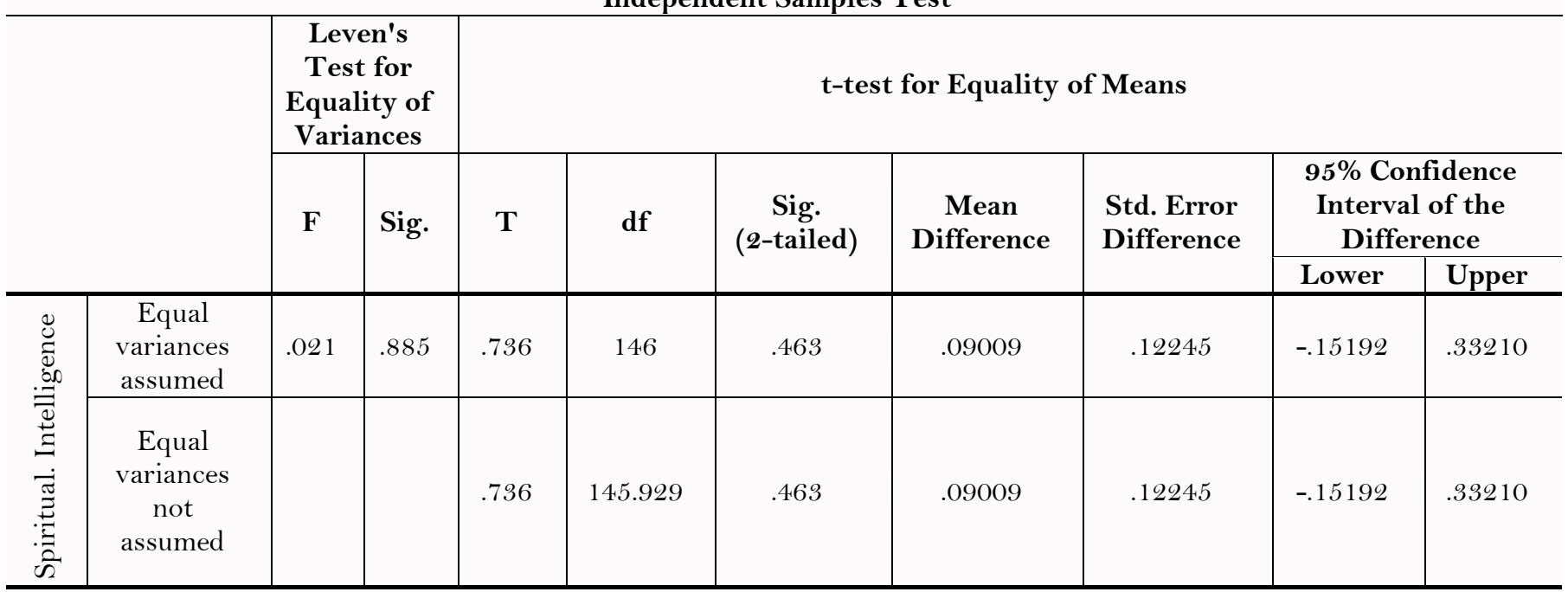

Table-5. Studying the difference between the team of trained team and individual sports students of Trabzon University in the optimistic variable.

\begin{tabular}{|c|c|c|c|c|c|c|c|c|c|c|}
\hline \multicolumn{11}{|c|}{ Independent Samples Test } \\
\hline & & $\begin{array}{l}\text { Level } \\
\text { for } \mathrm{E} \\
\text { of } \mathrm{Va}\end{array}$ & $\begin{array}{l}\text { Test } \\
\text { lity } \\
\text { ices } \\
\end{array}$ & \multicolumn{7}{|c|}{ t-test for Equality of Means } \\
\hline & & \multirow[t]{2}{*}{$\mathbf{F}$} & \multirow[t]{2}{*}{ Sig. } & \multirow[t]{2}{*}{$\mathbf{t}$} & \multirow[t]{2}{*}{ df } & \multirow{2}{*}{$\begin{array}{c}\text { Sig. } \\
(2- \\
\text { tailed) }\end{array}$} & \multirow[t]{2}{*}{$\begin{array}{c}\text { Mean } \\
\text { Difference }\end{array}$} & \multirow[t]{2}{*}{$\begin{array}{l}\text { Std. Error } \\
\text { Difference }\end{array}$} & \multicolumn{2}{|c|}{$\begin{array}{l}\text { 95\% Confidence } \\
\text { Interval of the } \\
\text { Difference }\end{array}$} \\
\hline & & & & & & & & & Lower & Upper \\
\hline 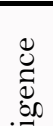 & $\begin{array}{c}\text { Equal } \\
\text { variances } \\
\text { assumed }\end{array}$ & 1.286 & .259 & 2.196 & 146 & .030 & .22973 & .10463 & .02294 & .43652 \\
\hline 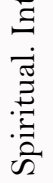 & $\begin{array}{c}\text { Equal } \\
\text { variances } \\
\text { not assumed }\end{array}$ & & & 2.196 & 138.141 & .030 & .22973 & .10463 & .02284 & .43662 \\
\hline
\end{tabular}

According to the results of the above Table 5, according to the significance level [Sig. (2-tailed) or P], which is less than 0.05, it can be concluded that there is a significant difference between the students of team and individual sports of Trabzon University in the optimistic variable. Regarding the average optimism for the group of sports, which was 2.68 and 2.91 for individual sports, it can be concluded that the observed significant difference was due to greater optimism in the group of sports students Individually.

Table-6. Studying the difference between trained team and individual sports students of Trabzon University in creativity variable in sport activity

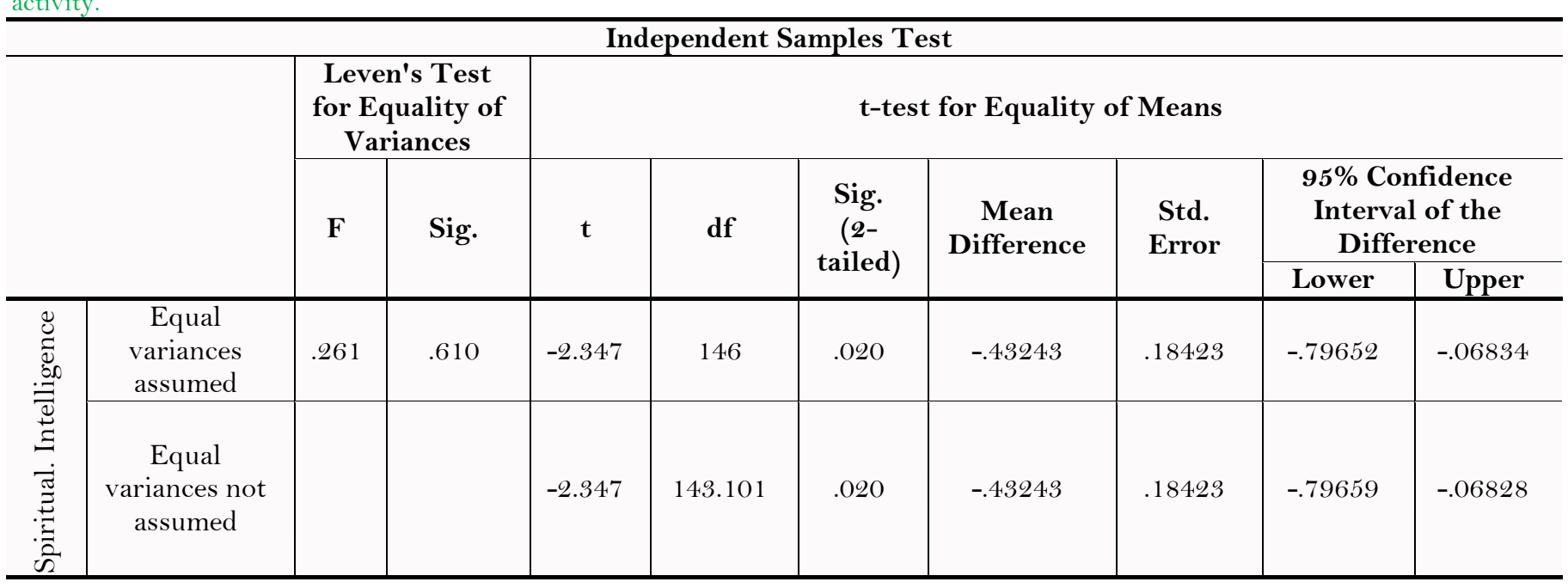

According to the results of Table 6, according to the significance level [Sig. (2-tailed) or P], which is less than 0.05 , it can be concluded that there is a significant difference between the students of team and individual sports of Trabzon University in the creative variable in sports activities. Regarding the average of creativity in sports activities for the group of sports, which was 2.67 and for the individual sports group, which was 2.24, it can be concluded that the significant difference observed from the higher level of creativity in sports activities In the case of students, he has been a group of sports. 


\section{Results}

In this research, the effect of spiritual intelligence and optimism on creativity in team trained and individual sports activities of Trabzon University students was investigated. The results showed that, due to the significant level of test error, sig. Or p, which for both variables "spiritual intelligence" and "optimism" was less than 0.05; spiritual intelligence and optimism on creativity had a significant positive effect on teamwork and individual sport activities of Trabzon University students (all students).

Also, the beta coefficient showed that the highest predictive power with the coefficient of 0.379 is related to the spiritual intelligence variable, followed by the "optimism" variable with a beta coefficient of 0.326 , which is creativity in teamwork and individual sport activities of students Trabzon University is predicting. It could be concluded that the variable "spiritual intelligence" affects and improves slightly more than the "optimism" variable on creativity in teamwork and solitary sports activities (all students).

That is, if people have high spiritual intelligence and have a spiritual feel for sporting activities and they have meaning, purpose and satisfaction, and they are optimistic and hopeful about their activities, in relation to Sports activities and problems, obstacles and issues will be more creative, and will choose more innovative and innovative ways.

In terms of team sports, if people have a high spiritual intelligence and spiritual experience in sporting activities, and they have meaning, goal and satisfaction, as well as the optimism of a team career, and Hope to be more creative and more creative and innovative, with sporting activities and problems, obstacles and issues. The results of this section were aligned with Almajali (2009); Rostami and Hayedeh (2014) and Baumgartner et al. (2018).

Also, the results showed that, due to the significant level of test error, sig. or p, which for both variables "spiritual intelligence" and "optimism" was less than 0.05; spiritual intelligence and optimism on creativity had a significant positive effect on the team sports activities of Trabzon University students. Also, beta coefficient showed that the highest predictive power with the coefficient of 0.436 relates to the variable "spiritual intelligence" and then the "optimism" variable with a coefficient of 0.434 is beta that creativity in team sports activities of university students Trabzon is predicted.

Also, in relation to solitary sports, if people have a high spiritual intelligence and spiritual sensation in their sporting activities, and they have meaning, purpose and satisfaction, as well as optimistic individual activities And hope that they will act more creatively with sporting activities and problems, barriers and issues, and will choose more innovative and innovative ways. It can be concluded that the variable "spiritual intelligence" affects and improves the "optimism" variable on creativity in team sports activities of students.

The results of this section were consistent with MacDonald and Bigelow (2010); Kalantarkousheh et al. (2014) and Hilary et al. (2016).

In the case of individual sports, the results also showed that, due to the significant level of test error, sig. or p, which for both variables "spiritual intelligence" and "optimism" was less than 0.05; the highest predictive power with a coefficient of 0.328 corresponds to the variable "spiritual intelligence" and then the "optimism" variable with beta coefficient 0.292 , which predicts creativity in individual sports activities at Trabzon University students. It can be concluded that the variable "spiritual intelligence" affects and improves the "optimism" variable on creativity in solitary sports activities of students. The results of this section were consistent with the research by Matthews (2011); Kalantarkousheh et al. (2014) and Yang and Mao (2007).

The results of the study showed that there was no significant difference between the students of team trained and individual sports of Trabzon University in the spiritual intelligence variable in studying the difference between the students of team and individual sports of Trabzon University in the spiritual intelligence variable.

Given the significant level [Sig. (2-tailed) or P], which was less than 0.05 , said that there was a significant difference between the students of team and individual sports of Trabzon University in the optimistic variable, so that the observed significant difference was due to the higher likelihood the nose was for the students of the individual sports band.

Given the significant level [Sig. (2-tailed) or P], which was less than 0.05; there were also significant differences between sport and team students at Trabzon University in creating creativity in sports. As a result, there was a significant difference between the more creativity in the sports activities of the students in the team of team sports.

\section{References}

Almajali, H.K., 2009. The influence of family upbringing style and locus of control on the creative thinking of preparatory school learners in the United Arab Emirates. Unpublished Doctoral Dissertation, University of South Africa.

Amram, Y. and C. Dryer, 2008. The integrated spiritual intelligence scale (ISIS): Development and preliminary validation. 116 th Annual Conference of the American Psychological Association. Boston, MA. Available from: http://www.yosiamram.net/papers.

Baumgartner, J.N., T.R. Schneider and A. Capiola, 2018. Investigating the relationship between optimism and stress responses: A biopsychosocial perspective. Personality and Individual Differences, 129: 114-118.Available at: https://doi.org/10.1016/j.paid.2018.03.021.

Brink, N.H., 2004. Locus of control and creativity in late middle childhood. Potchefstroom: North-West University.

Gabriel, C.L., R. Vilar, P. Hanel, R.P. Monteiro, M.G. Ribeiro and V.V. Gouveia, 2018. Optimism scale: Evidence of psychometric validity in two countries and correlations with personality. Personality and Individual Differences, 134: 245-251.

Hilary, G., C. Hsu, B. Segal and R. Wang, 2016. The bright side of managerial over-optimism. Journal of Accounting and Economics, 62(1): 46-64.Available at: https://doi.org/10.1016/j.jacceco.2016.04.001.

Kalantarkousheh, S.M., N. Sharghi, M. Soleimani and S. Ramezani, 2014. The role of spiritual intelligence on organizational commitment in employees of universities in Tehran Province, Iran. Procedia-Social and Behavioral Sciences, 140: 499-505.Available at: https://doi.org/10.1016/j.sbspro.2014.04.460.

Kalischuk, R.G. and K. Thorpe, 2002. Thinking creatively: From nursing education to practice. The Journal of Continuing Education in Nursing, 33(4): 155-163.Available at: https://doi.org/10.3928/0022-0124-20020701-06.

Kelberer, L.J., M.A. Kraines and T.T. Wells, 2018. Optimism, hope, and attention for emotional stimuli. Personality and Individual Differences, 124: 84-90.Available at: https://doi.org/10.1016/j.paid.2017.12.003.

Luftig, R.L., 2000. An investigation of an arts infusion program on creative thinking, academic achievement, affective functioning, and arts appreciation of children at three grade levels. Available from www.eric.ed.gov. 
MacDonald, N.M. and S. Bigelow, 2010. Teaching for creativity through fashion design. Journal of Family and Consumer Sciences, 102(2): 48-53.

Matthews, M.L., 2011. Connecting creativity and critical thinking to the campaign planning process. Journal of Communication Teacher, 25(1): 61-67.Available at: https://doi.org/10.1080/17404622.2010.527299.

Rostami, A.M. and C.G. Hayedeh, 2014. Prediction of marital satisfaction based on spiritual intelligence. Procedia - Social and Behavioral Sciences, 116(21): 2573-2577.Available at: https://doi.org/10.1016/j.sbspro.2014.01.613.

Shepperd, J.A., G. Pogge and J.L. Howell, 2017. Assessing the consequences of unrealistic optimism: Challenges and recommendations. Consciousness and Cognition, 50: 69-78.Available at: https://doi.org/10.1016/j.concog.2016.07.004.

Silingiené, V. and S. Škeerienè, 2015. Expression of leaders' spiritual intelligence in a context of service organizations: A gender approach. Procedia-Social and Behavioral Sciences, 213: 758-763.Available at: https://doi.org/10.1016/j.sbspro.2015.11.467.

Sindane, L.M., 2011. The relationship between happiness, creativity, personality and locus of control in Ireland for those who are employed and unemployed. Irland: Dublin Business School.

Torrance, E.P., 2000. Research review for the torrance tests of creative thinking fig-uraland verbalforms A and B. Bensenville, IL: Scholastic Testing Services.

Upadhyay, S. and N. Upadhyay, 2016. A multi-criteria decision framework to measure spiritual intelligence of university teachers. Procedia Computer Science, 91: 591-598.Available at: https://doi.org/10.1016/j.procs.2016.07.150.

Webber, K.C. and P.R. Smokowski, 2018. Assessment of adolescent optimism: Measurement invariance across gender and race/ethnicity. Journal of Adolescence, 68: 78-86.Available at: https://doi.org/10.1016/j.adolescence.2018.06.014.

Yang, K.-P. and X.-Y. Mao, 2007. A study of nurses' spiritual intelligence: A cross-sectional questionnaire survey. International Journal of Nursing Studies, 44(6): 999-1010.Available at: https://doi.org/10.1016/j.ijnurstu.2006.03.004. 